\title{
Defining the breaking point: Benefits and pitfalls of modeling long-term durability of a third-generation transcatheter valve in an era of short-term data
}

\author{
Jennifer J. Chung, MD, Samir Zaman, BS, Maria F. Arisi, BS, and Pavan Atluri, MD
}

From the Division of Cardiovascular Surgery, Department of Surgery, University of Pennsylvania, Philadelphia, $\mathrm{Pa}$.

Disclosures: Authors have nothing to disclose with regard to commercial support.

Zaman and Arisi contributed equally to this work.

Received for publication May 12, 2018; revisions received May 12, 2018; accepted for publication May 14, 2018; available ahead of print June 22, 2018.

Address for reprints: Pavan Atluri, MD, Hospital of the University of Pennsylvania, 3400 Spruce St, Silverstein 6, Philadelphia, PA 19104 (E-mail: Pavan.Atluri@uphs.upenn.edu).

J Thorac Cardiovasc Surg 2019;157:538-9

$0022-5223 / \$ 36.00$

Copyright (C) 2018 Published by Elsevier Inc. on behalf of The American Association for Thoracic Surgery

https://doi.org/10.1016/j.jtcvs.2018.05.051

As the indications for transcatheter aortic valve replacement (TAVR) continue to expand to lower-risk patients, understanding the tradeoffs between reducing procedure-related morbidity, and longer-term concerns of durability and structural failure, becomes increasingly salient (Table 1). The Edwards SAPIEN 3 valve (Edwards Lifesciences Corp, Irvine, Calif) is currently being evaluated for use in low-risk surgical patients with aortic stenosis in the Placement of Aortic Transcatheter Valves randomized trial (PARTNER) 3. Currently, there are limited data on the modes of failure of transcatheter bioprosthetic valves, with one systematic review identifying only 87 cases of failure between 2002 and 2014. ${ }^{1}$ Five-year follow-up of PARTNER 1 subjects showed no evidence of valve deterioration on echocardiographic examination, but is likely biased by its survival rate of $27.4 \%{ }^{2}$

While awaiting more clinical data on the outcomes of TAVR in a population with increased projected survival, Xuan et $\mathrm{al}^{3}$ provide a critical framework for identifying potential mechanisms of long-term failure of a 26-mm

\begin{tabular}{|c|c|}
\hline $\begin{array}{l}\text { Finite Element Analysis } \\
\text { - Models patterns of } \\
\text { deformation and } \\
\text { stress distribution on } \\
\text { leaflets } \\
\text { - Assumes uniform } \\
\text { pressure at fluid- } \\
\text { leaflet boundary } \\
\text { - Does not include } \\
\text { blood flow dynamics } \\
\text { past valve }\end{array}$ & $\begin{array}{l}\text { Fluid-Structure Interaction } \\
\text { - Couples structural } \\
\text { analysis of valve } \\
\text { apparatus and fluid } \\
\text { dynamic analysis } \\
\text { - Estimates leaflet } \\
\text { deformation and stress } \\
\text { patterns } \\
\text { - Can model flow } \\
\text { dynamics through valve }\end{array}$ \\
\hline prediction. & etic valve du \\
\hline
\end{tabular}

\section{Central Message}

Advanced computational models of transcatheter aortic valves provide a preliminary platform that can eventually integrate clinical data to more accurately predict valve degeneration patterns.

See Article page 528 .

SAPIEN 3 valve, in an elegant study analyzing the distribution of stress across the valve components. Using the computational method of finite element analysis (FEA), the authors used primary data on the material properties of the bovine pericardium valve leaflets to simulate the deformation of the SAPIEN 3 valve in a closed configuration in systole and diastole. Using this model, areas subjected to the greatest maximum principal stress (tension/tearing force) and minimum principal stress (compression/bending force) have been localized to the leaflets' sutured edge at the commissure and might indicate potential foci of calcification and leaflet degeneration. ${ }^{4}$

TABLE 1. Evolution of Edwards transcatheter bioprosthetic aortic valves

\begin{tabular}{|c|c|c|c|}
\hline & First-generation & Second-generation & Third-generation \\
\hline Name & SAPIEN THV & SAPIEN XT & SAPIEN 3 \\
\hline $\begin{array}{l}\text { Delivery catheter } \\
\text { (transfemoral) }\end{array}$ & $22-\mathrm{F}$ or $24-\mathrm{F}$ & $18-\mathrm{F}$ or $16-\mathrm{F}$ & $14-\mathrm{F}$ \\
\hline Design implementations & Stainless steel stent & Cobalt chromium stent & $\begin{array}{l}\text { Cobalt chromium frame structure redesigned; outer seal } \\
\text { skirt added }\end{array}$ \\
\hline Problems addressed & & $\begin{array}{l}\text { More compressible frame } \\
\text { results in fewer vascular } \\
\text { bleeding complications }\end{array}$ & $\begin{array}{l}\text { New frame allows access to coronary arteries for future } \\
\text { procedures; outer sealing skirt reduces risk of } \\
\text { moderate or severe paravalvular leaks; lower profile } \\
\text { further reduces vascular complications }\end{array}$ \\
\hline Issues & $\begin{array}{l}\text { Large sheath size required; } \\
\text { cannot be repositioned }\end{array}$ & $\begin{array}{l}\text { Sheath size still results } \\
\text { in some complications; } \\
\text { cannot be repositioned }\end{array}$ & $\begin{array}{l}\text { Outer seal skirt might affect bundle branches in some } \\
\text { patients and result in higher frequency of pacemaker } \\
\text { implantation; cannot be repositioned }\end{array}$ \\
\hline
\end{tabular}

SAPIEN valves are from Edwards Lifesciences Corp (Irvine, Calif). $F$, French. 
To fully understand the implications of the FEA model developed in this study, it is important to note the limitations of this method, which omits blood flow dynamics, thereby ignoring variation in pressure load and flow-induced shear stress on the leaflets. ${ }^{5}$ An alternative method of dynamic simulation, fluid-structure interaction analysis, couples the structural and fluid domains of the valve. This characterizes the stress distribution across the valve as well as the kinematics of leaflet deformation during the cardiac cycle, but might oversimplify the modeling of the structural domain. ${ }^{6,7}$ FEA, as used in this study, satisfactorily represents the nonlinear stress-strain relationship and mechanical anisotropy of valve leaflets, especially in the newly deployed configuration before degeneration. Follow-up studies that incorporate the effects of calcification and degeneration of the valve over time, might benefit from the additional use of fluid-structure interaction techniques to better elucidate abnormal hemodynamics.

As TAVR continues to rapidly evolve, it is important to consider new metrics to define success. If valve-in-valve options prove to be a satisfactory method of reintervention in cases of structural valve failure, the durability of transcatheter aortic valves need not achieve the same standards as surgically implanted valves. However, alternative modes of failure, such as valve thrombosis, late embolization, and endocarditis, will likely require continued refinement of procedural techniques and evolution of valve design. Xuan et $\mathrm{al}^{3}$ have provided a solid framework by which to identify expected areas of structural failure in the SAPIEN 3, and further clinical data will further improve the accuracy and prediction potential of computational models, with great implications for eventual development of a simulation-based tool to select the most appropriate patients for TAVR.

\section{References}

1. Mylotte D, Andalib A, Theriault-Lauzier P, Dorfmeister M, Girgis M, Alharbi W, et al. Transcatheter heart valve failure: a systematic review. Eur Heart J. 2015;36: 1306-27.

2. Kapadia S, Leon M, Makkar R, Tuzcu EM, Svensson LG, Kodali S, et al. 5-year outcomes of transcatheter aortic valve replacement compared with standard treatment for patients with inoperable aortic stenosis (PARTNER 1): a randomised controlled trial. Lancet. 2015;385:2485-91.

3. Xuan Y, Dvir D, Wang Z, Mizoguchi T, Ye J, Guccione JM, et al. Stent and leaflet stresses in 26-mm, third-generation, balloon-expandable transcatheter aortic valve. J Thorac Cardiovasc Surg. 2019;157:528-36.

4. Rodriguez-Gabella T, Voisine P, Puri R, Pibarot P, Rodes-Cabau J. Aortic bioprosthetic valve durability: incidence, mechanisms, predictors, and management of surgical and transcatheter valve degeneration. J Am Coll Cardiol. 2017;70:1013-28.

5. Luraghi G, Wu W, De Gaetano F, Rodriguez Matas JF, Moggridge GD, Serrani M, et al. Evaluation of an aortic valve prosthesis: fluid-structure interaction or structural simulation? J Biomech. 2017;58:45-51.

6. Wu W, Pott D, Mazza B, Sironi T, Dordoni E, Chiastra C, et al. Fluid-structure interaction model of a percutaneous aortic valve: comparison with an in vitro test and feasibility study in a patient- specific case. Ann Biomed Eng. 2016;44: 590-603.

7. Chandran KB. Role of computational simulations in heart valve dynamics and design of valvular prostheses. Cardiovasc Eng Technol. 2010;1:18-38. 